\section{MUJER Y CIENCIA}

\author{
Margarita Salas \\ Centro de Biología Molecular "Severo Ochoa" \\ (CSIC-UAM)
}

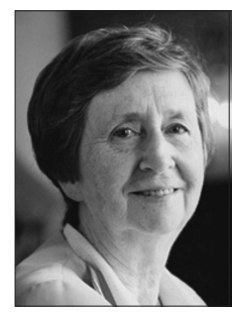

La mujer ha participado en la ciencia desde la antigüedad aunque, en general, su papel ha sido básicamente desconocido y sólo algunos nombres de científicas notables han llegado hasta nuestros días.

En el libro de Margaret Alic titulado "Historia de las mujeres en la ciencia desde la antigüedad hasta finales del siglo XIX", la autora escribe: "Nuestras primeras antepasadas aprendieron a preparar barro y hornear cerámica, y descubrieron la química de los esmaltes. Con el tiempo, los hornos de alfarería de las primeras ceramistas Ilegaron a convertirse en las forjas de la Edad de Hierro. Para la época de Cro-Magnon, las mujeres ya fabricaban joyería y mezclaban cosméticos, origen de la ciencia química" (1).

La llegada de la civilización griega (600 a.C.) permitió a la mujer participar en la escuela matemática de Pitágoras. Sin embargo, en la Grecia clásica las mujeres vivían, en general, confinadas en el mundo del hogar ya que existía la opinión, apoyada por personas ilustres como Aristóteles, de la inferioridad del sexo femenino.

A pesar de ello, se conocen algunos nombres como el de Agnodice (siglo IV a.C.), quien destacó en al campo de la ginecología, pero también por haber sido protagonista de una de las primeras rebeliones femeninas. Como a las mujeres no se les permitía estudiar medicina, se disfrazó de hombre para conseguirlo. Ejerció la ginecología sin revelar su identidad de mujer y sus éxitos profesionales despertaron la envidia de otros médicos que la acusaron de abusar de sus pacientes. Fue llevada ante los tribunales y tuvo que confesar su sexo por lo que fue acusada de violar la ley. Pero las mujeres a las que había curado la defendieron y consiguieron que la ley fuese abolida.

La llegada del Imperio Romano desplazó el Centro de la cultura de Grecia a Egipto, en especial a Alejandría, donde se conocen dos mujeres científicas importantes.
Una de estas mujeres fue María la Hebrea (siglo I a.C.), primera mujer cuyos escritos se conservan. Se distinguió por su habilidad para diseñar aparatos químicos, como el baño María que debe a ella su nombre. Como química destacó en el campo de los pigmentos, siendo su contribución más importante la del "Mary's Black", una preparación de sulfuro de cobre y plomo usado en pintura.

La otra mujer científica, la más conocida de la antigüedad, es Hypatia de Alejandría (370-415 a.C.), primera mujer científica que hizo contribuciones sustanciales al desarrollo de las matemáticas, cuya obra se conoce con detalle. Hypatia recibió la formación inicial de su padre, Teón de Alejandría, conocido matemático y filósofo. Después de estudiar en Atenas y en Italia, Hypatia volvió a Alejandría, ocupando un puesto en la academia Neoplatónica. Hypatia destacó en matemáticas y astronomía, aunque también cultivó la física, química y medicina. Entre sus obras principales destacan trece volúmenes de comentarios a la Aritmética de Diofano, y el Corpus Astronómico, tablas sobre los movimientos de los cuerpos celestes. Además, Hypatia también era experta en mecánica y tecnología, como se desprende de sus dibujos de instrumentos científicos. Como es bien sabido, Hypatia tuvo una muerte trágica.

Pasando a la Edad Media, la vida monástica hizo posible que las mujeres estudiaran y tuvieran libertad intelectual. Es de destacar Hildegard de Bingen (1098-1179), quien fue abadesa de un convento benedictino. Sus obras en el campo científico como el Liber Scivias, que incluye su primera cosmología completa, o la enciclopedia de historia natural titulada Physica, influyen sobre el pensamiento científico hasta el Renacimiento.

La creación de las universidades entre los siglos XII al XV hicieron que disminuyesen las oportunidades de formación de las mujeres, que habian estado centradas en los con- 
ventos. Hay que decir que las universidades más abiertas fueron las italianas.

La presencia de las mujeres en el mundo científico, se produce durante la revolución científica del siglo XVII. En esta época las mujeres están presentes en todos los campos científicos: química, matemáticas, astronomía, biología, geología y botánica, además de medicina, donde más habian destacado anteriormente.

De acuerdo con los historiadores, el establecimiento de las Academias constituye el origen de la Ciencia moderna. Las principales Academias europeas se fundan en el siglo XVII: en 1662 la Royal Society de Londres, en 1666 la Academie Royale des Sciences de París, en 1700 la Societas Regia Scientiarum de Berlín. A finales del siglo XVIII existían en Europa un número considerable de Academias, que eran instituciones vinculadas a las universidades. A medida que el prestigio de las Academias aumentaba, las mujeres eran excluidas de ellas. Así, la Academia Royale des Sciencies de París impidió que las mujeres entrasen como miembros de número. Aunque la Royal Society de Londres tenía unos estatutos más abiertos, no admitió a ninguna mujer hasta 1945.

En España, se creó la Academia de Matemáticas de Madrid en 1582 durante el reinado de Felipe II. En 1713 se fundó la Real Academia Española que, en los planes de su promotor, el marqués de Villena, debería abarcar todas las ciencias, aunque este propósito no se realizó. Se fundó, en cambio, en 1734, la Real Academia de Medicina y Ciencias Naturales. Después de un siglo, en 1834, se creó la Real Academia de Ciencias Naturales de Madrid, separándose de la de Medicina, y finalmente en 1847 se creó la actual Real Academia de Ciencias Exactas, Físicas y Naturales, quedando suprimida la anterior.

Si la primera mujer científica entró en la Royal Society en 1945, la primera que entró en la Real Academia de Ciencias Exactas, Físicas y Naturales, no lo fue hasta 1988. Este año, tomó posesión como Académica numeraria la segunda mujer en esta Real Academia que tiene un total de 52 Académicos. Otras Academias, como la de Medicina, tiene tan solo una Académica numeraria de un total de 44 Académicos, la Academia de Ingeniería tiene tres Académicas numerarias, siendo la Academia de Farmacia la que más Académicas numerarias tiene: 5 de un total de 48 Acadé- micos. Es decir, si sumamos el número de Académicas en las distintas Academias relacionadas con las Ciencias hay tan solo 11 Académicas numerarias de un total de cerca de 200 Académicos.

Se conocen algunos casos de mujeres que pudieron publicar sus trabajos en algunas Academias o que fueron reconocidas de algún modo por ellas. Así, Gabrielle-Emilie de Chatelet (1706-1749), una de las primeras personas que popularizó la física de Newton, pudo publicar en 1738 su trabajo sobre la propagación del fuego en las Actas de la Academia Royale des Sciencies de Paris. En un escrito que dirigió a Federico de Prusia le decía: "Juzgadme por mis propios méritos o por la falta de ellos, pero no me consideréis como un mero apéndice de este gran general o de aquel renombrado estudioso, de tal estrella que relumbra en la corte de Francia o de tal autor famoso. Soy yo misma una persona completa, responsable solo ante mi por todo cuanto soy, todo cuanto digo, todo cuanto hago" y termina: "así que, cuando sumo el total de mis gracias, confieso que no soy inferior a nadie".

Por otra parte la Royal Society de Londres publicó, a partir de 1787, los seis trabajos de Caroline Herschel sobre el descubrimiento de cometas. En 1828, a los 75 años, ella completó su gran obra sobre la posición de casi 2500 nebulosas, trabajo que le hizo ganar la Medalla de Oro de la Royal Astronomy Society. En su 96 aniversario el Rey de Prusia concedió a Caroline la Medalla de Oro de las Ciencias por su trayectoria de toda una vida. Murió a los 98 años.

Es en el siglo XX cuando las mujeres confirman su papel en el mundo de la investigación, aunque el número de científicas que han alcanzado el máximo reconocimiento, como el Premio Nobel, sea aún muy escaso.

La primera de estas mujeres es Marie Curie. Como de ella se hablará extensamente en otros capítulos sólo voy a comentar que fue la primera persona que recibió el Premio Nobel dos veces. Primero de el de Física en 1903 compartido con su marido Pierre Curie, y después, en 1911, Marie Curie recibió el Premio Nobel de Química.

En 1934 Marie Curie moría de leucemia a los 67 años. Un año más tarde, su hija Irene, casada con el también físico Frederic Joliot, recibió, junto con su marido, el Premio 
Nobel de Física por sus investigaciones sobre la producción artificial de elementos radiactivos. En 1938, su investigación sobre la acción de los neutrones sobre los elementos pesados fue un paso importante en el descubrimiento de la fisión del uranio.

Otro caso de científica notable es el de Barbara McClintock (1902-1992). Inició sus estudios en la Universidad de Cornell en 1919, doctorándose en 1927 en el Departamento de Genética, donde no fue admitida de un modo oficial, ya que no estaba prevista la admisión de mujeres. En aquellos tiempos la Genética era una ciencia hecha por los hombres. De hecho, en la Universidad de Cornell no se nombró profesora a una mujer hasta 1947, excepto en el Departamento de Economía Doméstica. Son los momentos iniciales de los estudios genéticos sobre el maíz, y Barbara McClintock encuentra un puesto de trabajo como ayudante de laboratorio de un profesor que llevaba dos años intentando teñir los cromosomas de esta planta. Barbara McClintock resuelve el problema en tres días, atrevimiento que motivó que fuera despedida del empleo. Finalmente, consigue un lugar de trabajo en los laboratorios Cold Spring Harbor en el estado de Nueva York, es elegida en 1944 miembro de la Academia Nacional de Ciencias de Estados Unidos, en 1945 ocupa el puesto de Presidenta de la Genetic Society of America y en 1983, por el descubrimiento de la transposición genética, los popularmente llamados "genes saltarines", consigue a sus 81 años un tardío pero merecido Premio Nobel de Medicina.

Otras doce científicas consiguen el Premio Nobel de Física, de Química o de Medicina: se trata de Gerty Cori, quien nació en Praga y emigró a Estados Unidos. En 1947, junto a su marido Carl Cori, obtuvo el Premio Nobel de Medicina por sus investigaciones sobre la síntesis biológica del glucógeno y el mecanismo de acción de la insulina; sin embargo, como en el caso de Pierre y Marie Curie, fue Carl Cori el que obtuvo la cátedra y no Gerty, quien obtuvo solo un puesto de asociada con un sueldo que era el 10\% del de su marido; María Goeppert Mayer, quien obtuvo en 1963 el Premio Nobel de Física por sus estudios sobre las propiedades de los núcleos atómicos; Dorotty Crowfoot Hodkin, recibió el Premio Nobel de Química en 1964 por su determinación de estructuras de gran trascendencia biológica, tales como la insulina, el colesterol, la penicilina y la vitamina B12 después de haber sido nombrada miembro de la Royal Society, de la Real Academia Ho- landesa de las Ciencias y de la Academia Americana de Artes y Ciencias; Rosalyn Sussman Yalow, obtuvo el Premio Nobel de Medicina por sus investigaciones que llevaron al perfeccionamiento de la determinación radioinmunológica de alta intensidad; Rita Levi Montalcini, italiana, se tuvo que trasladar a Estados Unidos después de la segunda guerra mundial debido a la persecución que sufrió por su condición de judia, descubriendo el factor de crecimiento neurológico, lo que le valió el Premio Nobel de Medicina en 1986, a los 77 años; Gertrude Belle Elion, obtuvo el Premio Nobel de Medicina en 1988 por sus estudios sobre fármacos contra diversas enfermedades como la leucemia; Christiane Nuesslein Volhard, nacida en Alemania en 1942 obtuvo en 1995 el Premio Nobel de Medicina por sus estudios sobre genética del desarrollo utilizando como sistema la mosca del vinagre, Drosophila melanogaster; más recientemente, en 2004, Linda Buck por sus estudios sobre las proteínas implicadas en el sistema del olfato; en 2008, Francois Barré-Sinoussi por su descubrimiento del virus del SIDA; finalmente, en 2009, tres mujeres han recibido el Premio Nobel, dos, Elisabeth Blackburn y Carol Greider el de Medicina por su descubrimiento de los telómeros y la telomerasa, y Ada Yonath el de Química, por la determinación de la estructura tridimensional del ribosoma.

Estas 15 mujeres son las únicas que han llegado a la cúspide en el área de las Ciencias, considerando la cúspide la obtención del Premio Nobel. Frente a estas 15 mujeres, más de 300 hombres han obtenido el Premio Nobel en dicha área.

Otras científicas muy valiosas tuvieron menos suerte que las anteriores y no consiguieron un merecido Premio Nobel. Entre ellas destaca Rosalind Franklin. Su trabajo fue básico en el descubrimiento de la estructura de doble hélice del DNA por Watson y Crick. Sin embargo, en parte debido a su muerte prematura (murió de cáncer a los 37 años) y en parte debido a su condición de mujer, lo cierto es que la historia no le ha hecho justicia. Sólo más recientemente se ha empezado a reconocer su contribución con ocasión del 50 aniversario de la doble hélice.

Otra científica que también destaca por sus importantes contribuciones en el campo de la Física es Lise Meitner (1878-1968). Austríaca de nacimiento y alemana de adopción, su sangre judía hace que tenga que emigrar a Suecia. Llamada por Einstein "la Marie Curie alemana" su 
nombre ha quedado vinculado al de la física nuclear. Según comenta Otto Hahn, quien formó un excelente tandem con Lise Meitner: "El comienzo fue difícil para ella. Emil Fisher, el Director del Instituto de Química en Berlín, no aceptaba a las mujeres, pero hizo una excepción en favor suyo, con la condición de que no entrara en laboratorios donde trabajaban estudiantes varones". Fue la segunda mujer que en Viena alcanzó el título de doctor en Física, en 1906, y también la segunda que obtuvo la venia legendi en Física por una Universidad alemana. Como anécdota, la conferencia pronunciada por Lise Meitner en 1922 al obtener la venia legendi por la Universidad de Berlín titulada "Problemas de Física Cósmica" apareció en la prensa con el título "Problemas de Cosmética Física".

Aunque Lise Meitner fue clave en el descubrimiento de la fisión nuclear, el Premio Nobel de Química fue obtenido en 1944 por su compañero de trabajo Otto Hahn quien reiteradamente ocultó la contribución de Lise Meitner, quedando ésta en el olvido.

Otras dos científicas del siglo XX a las quiero mencionar son Kathleen Lonsdale y Marguerite Perey.

Kathleen Lonsdale desarrolló la mayor parte de su actividad científica en el University College de Londres, donde fue la primera mujer profesora, siendo a su vez la primera mujer elegida miembro de la Royal Society en 1945, y la primera mujer presidenta de la Asociación Británica para el Avance de las Ciencias. Entre sus trabajos más importantes se encuentra el descubrimiento de la estructura plana del benceno.

Marguerite Perey perteneció a la escuela francesa de radioquímica iniciada por Marie Curie. En 1939 descubrió el francio, denominado en honor a su país de origen, último de los elementos químicos naturales. En 1949 fue nombrada titular de Química Nuclear en la Universidad de Estrasburgo. Fue la primera mujer miembro correspondiente de la Academia de las Ciencias de París, en 1962, desde su fundación por Luis XV en 1666. Es decir, tuvieron que pasar casi 300 años para que una mujer fuese nombrada miembro correspondiente, no numerario, de la Academia de Ciencias de París.

Aunque estamos en el año 2010, son todavía pocas las mujeres que forman parte de Academias de Ciencias en el ámbito europeo, con una media del 4\%. En España, como hemos visto antes, la proporción es similar.

En un trabajo de hace unos años, M. Jesús Santesmases, analiza una muestra de 48 científicas españolas, todas ellas doctoradas antes de 1970 en ciencias biológicas o biomédicas (2). Muy pocas de entre ellas han alcanzado el máximo reconocimiento profesional que han podido alcanzar sus colegas los hombres, y han estado dedicadas a actividades más propias del trabajo diario del laboratorio que de su dirección. Es decir, ha habido un reparto de roles dentro de los grupos de investigación entre hombres y mujeres que está en línea con el reparto de roles por sexo en el resto de las actividades y responsabilidades familiares y sociales de las personas.

Es obvio que hemos recorrido un camino importante en el que la mujer científica ya no es mirada como una rareza y también ha cambiado su mentalidad, pero también es cierto que el número de mujeres que en la actualidad alcanzan una posición directiva es muy bajo.

¿Como veo a la mujer científica en el mundo actual? Tengo que decir que en la actualidad el número de mujeres que realizan la tesis doctoral en nuestros laboratorios iguala y, en numerosos casos, sobrepasa al número de hombres. La mayoría de estas mujeres se plantean en la actualidad una carrera científica tan seria como la de los hombres. Yo no veo en este momento discriminación frente a las mujeres a la hora de conseguir una beca para hacer la tesis doctoral o para obtener un puesto de trabajo en nuestros centros públicos de investigación. Sin embargo, todavía existen desviaciones, en particular en los puestos más altos. En un artículo reciente se comenta que la mujer forma el 53\% de la Universidad, pero sólo ocupa el 34\% de las plazas de profesor titular y el 14\% de las Cátedras. Por otra parte, sólo 10 de los 73 Rectores actuales son mujeres y ningún Presidente del Consejo Superior de Investigaciones Científicas ha sido mujer.

De cualquier manera, es evidente que el número de mujeres científicas ha aumentado de una manera espectacular. Yo soy optimista $y$, debido al aumento del número de mujeres en los laboratorios de investigación pienso que si las mujeres seguimos luchando e incorporándonos al mundo profesional, en un futuro no muy lejano la mujer investigadora ocupará en la comunidad científica el puesto que le corresponda de acuerdo con su capacidad. 


\section{REFERENCIAS}

(1) Alic, M., Hypatia's Heritage: A History of Women in Science from Antiquity through The Nineteenth Century, Beacon Press, Boston, 1986.
(2) Santesmases, M. J., Mujeres científicas en España (1940-1970). Profesionalización y Modernización Social, Instituto de la Mujer, 2000. 